\title{
9. The Malfunctions of New Public Management: A case study of governance in Indigenous affairs ${ }^{1}$
}

\author{
Ian Marsh
}

Indigenous policy presents in acute form a case study of challenges to present public administration practice. Successive governments have promised to reduce extreme disadvantage and to do this in conjunction with affected citizens. ${ }^{2}$ But failures persist. In looking for explanations, Dr Peter Shergold (2006) has not only arraigned governance as a threshold cause but also set a high bar for its practice:

I am aware that, for some fifteen years as a public administrator, too much of what I have done on behalf of government for the very best of motives has had the very worst of outcomes ... In my personal opinion three things need to be done ... We need to tailor government programs to the particular circumstances of discrete communities ... We must ensure that discretionary government expenditures are negotiated to goals that address local needs ... Community challenges are almost invariably holistic in their nature and require a variety of programs from all three tiers of government to be delivered in a coordinated whole of government manner.

\footnotetext{
1 This is an abridged version of a paper prepared for the Alice Springs think tank Remote Focus in 2011 as part of a review of governance in remote Australia. The original paper, 'The Evolution of Governance in Remote Australia: From centralised and top-down towards contextualised and collaborative approaches', and the final report, 'Fixing the Hole in Australia's Heartland', are both available at www.desertknowledge.com.au.

2 For example, a recent policy statement (Australian Government 2011) states: 'Genuine engagement with Aboriginal and Torres Strait Islander Australians is fundamental to our efforts to improve life outcomes and close the gap in the indigenous disadvantage ... A critical step in improving outcomes for Aboriginal and Torres Strait Islander Australians is for government agencies, service providers and contractors to engage them as valued stakeholders in the development, design, implementation, monitoring and evaluation of policies, programs, services and legislation that have an impact on them.' Also in November 2011, the Commonwealth released its 'Indigenous Economic Development Strategy' which states: 'Government cannot act alone. Success depends on working in partnership with indigenous leaders communities and individuals and with business, industry peak bodies and non-government organizations.' Writing in 2005, Peter Shergold, the former Secretary of DPMC and a primary author of the current framework, observed: 'We need to drive governance programs in the direction of connectedness. Programs need to be made more flexible, responsive to community needs and priorities and delivered in a holistic manner ... More importantly, there needs to be a delivery of programs in a seamless manner to local communities' (2006).
} 
Such aspirations are echoed in more general terms in recent reports on broader public sector reform. At the federal level, such ideas figure prominently in the Moran Review (AGRGA 2010), and at a state level, in the Western Australian Economic Audit Committee Report (WAEAC 2009).

So how equipped is the Australian public service to meet such challenges? This chapter suggests there is a long way to go. Moreover, the central obstacles to their realisation lie in structural features that are keystones of new public management. Specifically:

- Governance arrangements are a threshold cause of policy failure in Indigenous affairs. As discussed later in detail, centralised protocols and siloed departments undercut local responsiveness. Reframed governance will not, of course, by itself solve the many problems of Indigenous disadvantage. That can ultimately only be achieved with the active involvement of the affected citizens. But this essential mobilisation is negated by the present governance framework and cannot be remedied within it.

- The challenge in designing new policies is a structural one. Local discretions in service delivery and decentralised governance designs are unattainable within the present protocols surrounding budgeting, siloed departments, human resources management and accountability arrangements. All these protocols need ultimately to be reworked if the circle is to be squared between local discretion, continuous improvement, and centralised accountability. Britain has begun to experiment in whole-of-government budgeting (NAO 2013). But ultimately the challenge goes deeper, perhaps ultimately to a framework that Charles Sabel has described as 'experimentalist governance' (for example, Sabel 2004; Sabel and Zeitlin 2011).

- The challenge in designing new policies is also a strategic one; a rethink from fundamentals is required (for example, Shergold 2013). This is first and foremost a challenge to imagination. A paradigm shift — one that challenges structurally embedded habits, practices, and approaches - will always be hard to accomplish. This is particularly hard in Australia's policy system which has few if any platforms that can host appropriate conversations and exchanges.

At the heart of this chapter is a simple claim: there is an imperative need to reframe governance. This composite concept recognises the essential interdependence between the formal apparatus of the state and its publics. The parties are engaged in a dynamic exchange, the opposite of directed, deferential, passive or paternalistic linkage. In achieving positive and sustainable outcomes, engagement has a primary rather than a secondary role. ${ }^{3}$ Compounding this

3 For a sensitive discussion of the complexity of choice in an Indigenous context, particularly the tensions between individualist and collectivist patterns, see Rowse 2002, 2012. 
challenge is the overlap of policy responsibilities between federal and state government. While present rhetoric gestures to the intergovernmental, systemic and contextual character of policy challenges, practice falls far short of stated ambitions.

Indigenous affairs display these difficulties in sharp relief. The following section explores the structural barriers which inhibit decentralised, whole-ofgovernment practice. This is followed by a review of responses elsewhere to analogous challenges. The conclusion evaluates the challenge of grafting such approaches into Australian public administration.

\section{What are the structural barriers to whole-of- government?}

Two official Management Advisory Committee reports (2004, 2007) noted five changes in organisation and processes that were deemed essential to underpin whole-of-government practice:

1. substantial initial cross-agency/stakeholder agreement about the broad purposes to be pursued;

2. use of the outcomes budget framework to pool resources and to create appropriate accountability frameworks;

3. lead-agency staff empowered with sufficient authority to manage whole-ofgovernment settings and to lead the engagement of local stakeholders;

4. empowering these same managers to engage with relevant individuals and interests; and

5. ensure the individuals engaged in these latter roles have the appropriate networking, collaboration and entrepreneurial skills.

\section{How did this unfold in Indigenous affairs?}

A first step involves assessment of the multitude and variety of programs that have been established to drive change in local communities. The 'Strategic Evaluation of Indigenous Programs' (Department of Finance 2010) offers the most recent comprehensive overview. It identified no less than 232 individual programs which in one way or another support Indigenous Australians. This report reviews these programs in the context of the various broad outcomes that the government has established. An earlier Australian National Audit Office (ANAO) report (2007) focused on the four primary departments: Department 
of Education and Science (DES), Department of Employment and Workplace Relations (DEWR), Department of Families, Community Services and Indigenous Affairs (FaCSIA), and Health and Ageing. This report identifies 94 programs, either mainstream or niche, that are relevant to Indigenous affairs. DES operates 15 Indigenous-specific programs and 43 mainstream programs that have Indigenous applications; DEWR operates 11 Indigenous-specific programs and the Job Network; FaCSIA operates six Indigenous-specific and six mainstream programs; Health and Ageing operates five Indigenous-specific programs and nine mainstream programs. To add to the complexity, many of these major programs have sub-components.

To coordinate funding, the federal government decided to establish Indigenous Coordinating Centres (ICCs) at a regional or area level. In practice, coordination can be achieved by one of two means: by brokering linkages between communities and programs; or by joining individual programs into a funding block, which is more demanding. Meantime, to test the model, trials at selected sites were introduced in 2003.

In a report on these trials, Gray (2006) explored the challenge of program management as perceived on-the-ground, in this particular case from Wadeye. The trial was intended to reduce the number of individual programs that local communities need to manage. In fact, in the course of the trial the number of relevant programs increased to 90. In another example, Dillon and Westbury (2007, p. 66) list the five Commonwealth programs that could be tapped to fund natural resource management on Indigenous land:

An important and growing policy area where in recent years scores of Indigenous ranger programs have emerged across northern Australia focused on land and resource management. Program funding in this area comes from a diverse array of agencies: the National Heritage Trust, the Indigenous Protected Areas Program, CDEP, STEP and the ABA ... Programs vary in size from hundreds of millions (for example the CDEP or ARHP) to less than half a million (for example the Indigenous Children's Program).

With 39 per cent of the Indigenous population under 15, education is another critical area. The same authors note the array of programs relevant here:

The national flagship programs include the Youth Allowance and Abstudy: the former is targeted at young people studying, undertaking training for Australian apprenticeship, looking for work, or sick; the latter at indigenous students. Over and above this, FaCSIA has four 'niche' programs which provide youth services of various kinds with a total national budget of $\$ 34.6$ million and a client base of approximately 
340000 nationally. DEST has at least ten youth related Indigenous specific niche programs ... the data on numbers of service providers suggests that the availability of these programs in remote Australia is very patchy ... It is clear that across the national government there are a couple of hundred different programs potentially allocable to the circumstances of remote citizens. Access is a different matter entirely (Dillon and Westbury 2007, pp. 67-68).

Finally, they note the bewildering array of programs aimed at Indigenous housing:

The existence of concurrent state and national responsibilities means that in some areas programs are duplicated by each jurisdiction. Housing is a classic example where states, territories and national governments deliver both mainstream and Indigenous housing and housing related programs, and even within the national government there are a number of separate Indigenous housing programs (CHIP/NAHS, CHIP/AACAP, $\mathrm{FHBH}$ ) all delivering housing and essential services at the community level, along with the Australian Regional Housing Programme which funds the states and territories to deliver housing at the community level (Dillon and Westbury 2007, p. 65).

The whole-of-government architecture was designed to ensure these programs are accessed by the citizens that they are intended to serve. How effective have these arrangements proven to be?

\section{Whole-of-government architecture}

Since whole-of-government arrangements were introduced in 2002, there have been at least nine reviews. The first four covered the initial COAG trials and the rest focused on subsequent developments. Seven were official or commissioned evaluations and the remainder were independent academic assessments: Urbis, Keys and Young 2006; Morgan Disney and Associates 2006; Gray and Sanders 2006; Gray 2006; ANAO 2007; KPMG 2007; Hunt 2007; FaHCSIA 2004; O’Flynn et al. 2011. All these reviews repeat points stressed in the Management Advisory Committee documents, namely that whole-of-government will not work without devolution of authority, funding, accountability and coordinated organisation. They also all found continuing and unresolved administrative difficulties.

As an introduction to these unresolved problems, consider the case of Mutitjulu, ironically the first community named in the Northern Territory Emergency Response (NTER). Before whole-of-government was conceived, this community tried, over more than a decade, to obtain for itself a new style of governance (Smith 2009). Its efforts foundered on immovable central structures. This 
story starts in 1991 when the Women's Council prepared a report highlighting concerns about 'controlling and caring for children'. A series of submissions and discussions followed. In 2000, the community council at Mutitjulu asked Centrelink, the Aboriginal and Torres Strait Islander Commission, and the then Department of Families and Community Services to work with it to develop a practical strategy to deal with welfare dependency and related family problems. Following a consultation, the Community Council itself proposed a Participation and Partnership Agreement. The departments did not respond. Why?

First, the key departments would not support an 'All in' community model of welfare reform and would not support linking Youth Allowance with school attendance, even though these had been specifically requested by community members ... Second, Centrelink and FACS would not countenance an indigenous community working with them to develop and implement locally-relevant breaching rules. Neither would they countenance a community organisation being provided with a delegation under the Social Security Act in order to do so ... Third, entrenched inter-departmental turf wars in Canberra meant that the departments concerned were unable to negotiate a common position ... And finally the Australian government was unable or unwilling to reform the chaotic state of its departmental program funding in order to streamline the pooled funding and grant reporting arrangements that would have been required ... In late June 2007, the Australian government announced that Mutitjulu would be the first community into which it activates national emergency measures. It will do so unilaterally (Smith 2009, p. 6).

So far as coordination is concerned, we will see little has changed.

The findings of the various evaluations affirm that whole-of-government is confounded at the critical regional and ICC levels. The obstacles are structural, not contingent. Consider the two most recent reports, an official report conducted by KPMG (2007) and an independent report conducted by academics from The Australian National University and the University of Canberra (O'Flynn et al. 2011). The KPMG study involved a review of internal documents as well as interviews with 158 Australian and state government agency staff and 35 community organisations. The report compared the proclaimed objectives of the policy with the experience and observations of local staff. Despite six years' experience and at least eight preceding reviews, structural obstacles to joinedup work persisted. Here is a summary:

- Departmental silos persisted: Line agency staff presented to communities/ organisations as representative of their agency. Communities/organisations 
reported that they did not know who to talk to. ICC staff and line agency staff rarely visit communities together (p. 19).

- Funding protocols prevented discussion with applicants: Many line agency staff were unable to provide governance and financial management assistance to organisations due to probity issues relating to assessment of funding applications (p. 21).

- ICC managers lacked authority: Managers indicated that they did not have authority to gather agency staff support. Line agencies confirmed that their staff remained their direct responsibility (p. 23).

- Funding and reporting arrangements inhibited whole-of-government collaboration: Line agencies have different program guidelines, funding rounds and delegations, and different risk assessment protocols. In some cases this resulted in applications undergoing up to eight different risk assessments (p. 29). One ICC took over 12 months to negotiate and approve an SRA which was worth under $\$ 50,000$ in funding (p. 32). One agency may apply more rigorous risk assessment for applications over $\$ 100,000$, while another agency's more rigorous assessment only applies to applications over $\$ 150000$ (p.34).

- The problems are structural: 'The implementation of whole-of-government collaboration in ICCs is an area requiring significant improvements. Many of the issues that impede whole-of-government are structure and have little to do with ICC staff and management's willingness to collaborate' (pp. 10, 29).

The findings of the university-based study (O'Flynn et al. 2011) echo these conclusions, albeit in more graphic terms. This study was based on 48 field interviews covering staff at ICCs, state and regional offices, and in Canberra. It suggests that, despite the top-down whole-of-government effort, Mutitjulu's experience has not been transcended. Their conclusion is unequivocal: 'Due to entrenched barriers, which permeate the broader public service, ICCs have been a failed experiment.'

Like KPMG, O'Flynn et al. identify structural failings in the basic organisational design:

- No or limited assignment of authority to the ICC managers,

- An ad hoc approach to the representation of departments (which meant staff were withdrawn as cost pressures emerged);

- An under-investment in skills; and

- Inconsistent operating systems.

They cite the comments of ICC managers, first on their delegations of authority:

I could not go out and direct another person to do something in this ICC ... because they're not from my agency. I could (only) ask, influence, beg (Executive Level, ICC: 248). 
Whole of government doesn't work ... when you've got all different agencies sitting in the one place, supposedly working together ... they're supposed to be all collaborating and telling each other what they're doing ... I'm telling you it doesn't work and I work in an ICC and I've been there since the day it started (Executive Level, ICC: 248).

The fact that we're co-located with [Department A] and [Department B] and a couple of [Department C's] people is just window dressing. So there's no whole of government activity between them ... There's no practical program [or] whole of government approach (APS Level, ICC: 248).

The NTER Review also picked up these criticisms but this time from the perspective of the clients:

There was extensive comment in communities about the lack of coordination across locally based professional staff. Between the GBMs, Community Employment Brokers and shire service managers, there is not a clear point of authority or coordination (p. 86).

A second set of unresolved governance issues arose from conflicting vertical and horizontal tensions which cut across in the administration of programs. According to O'Flynn et al.:

The pervasiveness of a program focus and the silos that it creates were seen as impossible to combat even in a setting where there was physical co-location and strong endorsement from Ministers and Secretaries (2011: 249).

A third problematic element involved centralised decision-making. This aspiration also fell foul of more embedded administrative practices and requirements:

The idea [was] for ICCs to have a pool of money that they could make decisions about. Well, in the great thing about being risk averse that was all centralised back in Canberra: ... useless basically. It just went against the whole thing about whole of government which is about sharing, devolving, not controlling everything, but taking responsibility and it's the same pattern. And that was a bit of its undoing, in fact because it was to give people the power to do the deal on the ground (Senior Executive Service, ICC, p. 249).

Most recently, under the 2009 National Partnership Agreements between the Commonwealth and the states, the same broad arrangements have been extended to coordinate the delivery of programs across jurisdictions. Six agreements have already been signed and others are foreshowed in relation to native title claims arrangements, remote infrastructure and healthy food. In general, the parties also 
commit to 'developing a co-ordinated approach', and 'enabling initiatives to be delivered in a manner appropriate to needs in particular locations'. To oversee the arrangements, a Coordinator-General based in Canberra was appointed in 2009. This position was abolished in 2014.

\section{Accountabilities as a structural barrier to local effectiveness}

Central accountability requirements create another barrier to on-the-ground effectiveness. Take health services. In the interests of enhancing local choice and control, the Aboriginal community controlled health services were established in the 1980s. Funding was later transferred to the Aboriginal and Torres Strait Islander Commission and grants were on a yearly basis, but with an expectation of continuance. The Commonwealth Department of Health assumed responsibility in 1995 and thereafter funding increased. The pattern of funding has since further evolved with most services now drawing support from several sources: a core operating grant from the Office for Aboriginal and Torres Strait Islander Health; state government health department grants; and by proposal driven niche-funding that could include broader social purposes.

Each funding source adopts its own application process, accountability framework and priorities. In an assessment of these arrangements, Lavoie et al. (2009, p. 6) note:

Analyses conducted by the Victorian Department of Health suggests that the reporting and compliance burden is disproportionate compared to that imposed on other small and medium-size funded agencies.

For example, Aboriginal agencies receiving on average \$2 million were accountable for between 26-30 activities. Non-governmental organisations typically received total funding of $\$ 10$ million for the same array of activities. This study also found that agencies can be required to produce up to 59 separate reports for 13 programs. This boosts transaction costs disproportionately. Further, in a small service, disentangling the daily time allocation of a single staff member between varieties of programs can be wholly artificial. Finally, a 12-month funding cycle makes the recruitment of staff precarious.

These multiple accountabilities and the associated burden of transaction costs have persisted despite having figured so strongly in other evaluations. This suggests that the requirements derive from wider structural imperatives and cannot be excised without systemic change. 


\section{Consultation and the development of social capital}

As noted at the outset, every official report since 2001 has emphasised the imperative of working with and through local communities (for example, Commonwealth Grants Commission 2001; Morgan Disney and Associates 2006; NTER Review 2008; Department of Finance 2010; Productivity Commission 2012). To illustrate the complexities that can arise, Edmunds (2010, p. 16) cites the negotiations over James Price Point, which involved Woodside and a proposed liquified natural gas development. Negotiations were conducted with the Kimberley Land Council, the organisation which had statutory responsibilities for consultation under the Native Title Act. The council had secured a consensus amongst key traditional owners. But a dissident group challenged these processes. Edmunds (2010, p. 16) comments:

This is a common situation and one that traditional law could once have dealt with. However, it fits uneasily into contemporary decision making, raising a crucial question about how much, and whose consent is needed for informed consent.

If this is one dimension of the issue, another is the quixotic (from the perspective of local communities) behaviour of their governmental interlocutors. Take the NTER, which banned sales of alcohol on Aboriginal land. According to Marian Brady, a specialist in alcohol use in Indigenous communities:

The (political grandstanding associated with the NTER) was a little strange considering that most Aboriginal land in the Territory was already dry. There were already 107 general restricted areas, all on Aboriginal land and all in non-urban areas except for one town camp in Alice Springs ... the alcohol recommendations in the Little Children are Sacred report ... are designed to work with and enhance the NTs existing legislative structure ... the Intervention measures unhelpfully cut across them (cited in Edmunds 2010, p. 19).

Another example involved the impact of the NTER at Wadeye, an early trial site:

When a crisis erupted at the Wadeye trial site ... the Commonwealth government resorted to a more coercive approach characteristic of hierarchical or contract government ... It has chosen not to develop housing through the legitimately elected Thamururr Regional Council, with whom it signed the COAG trial agreement thereby by-passing and potentially undermining the very indigenous governance structure it partnered with only four years ago, and to which it remains formally committed in the NT bilateral agreement (Hunt 2007, p. 167). 
Smith (2009) describes the proposed governance arrangements for the West Arnhem Shire that were developed slowly and after protracted negotiations that had begun in 2004. Their purpose was to plan implementation of a new local government shire covering the entire region. Following protracted onthe-ground negotiations over three years, which progressively built support amongst relevant groups and communities, a new governance structure had been settled. In 2007, the Intervention aborted these arrangements, leaving behind a frustrated and cynical local community.

According to the ANAO, in 2007, 75 per cent of 257 managers surveyed responded positively to the statement: 'The Indigenous Affairs Arrangements (IAAs) have encouraged consultation with indigenous communities at the local and regional levels.' How effective were these conversations from the perspective of their interlocutors? The on-the-ground evidence is not positive. For example, in May 2010, DEEWR and FaHCSIA issued a draft Indigenous economic strategy. Submissions were invited and consultations held with Indigenous communities throughout Australia. The following are the reporter's notes on the consultations held in various remote centres in November 2010. In Alice Springs, for example:

Approximately 22 (indigenous) participants attended the workshop ... People participated in both the questions and answer session and the table discussions but there was widespread criticism of the relevance of the Indigenous Economic Development Strategy to remote areas and the likelihood of anything changing on the ground ... There are no economic foundations in remote communities and this needs to be acknowledged ... There was widespread criticism that the strategy was homogenising and represented an urban western model ... (it) needs to respond to the different circumstances, opportunities, economies and drivers in remote regional areas...There are so many economic strategies around that people are blasé about 'just another plan' ... The gap between the strategy and what is happening on the ground is very wide ... There is a different sort of economy operating in remote areas. It's not just a matter of transferring these into real jobs, they are real jobs but not recognised as such.

The report records analogous sentiments from participants in all the other consultations sites covering Broome, Cairns, Port Lincoln and Karratha. Here is one more observation from Karratha:

Real engagement means listening to indigenous people and not just telling them ... previous feedback for policy development over the years has been ignored. There is no apparent correlation between what the Australian government proposes and what indigenous people want ... Different communities have different needs and opportunities. 


\section{The overall funding framework}

At a material level, W. H. Stanner's indictment of the 'great Australian silence' in relation to Indigenous Australians is reflected in the legacy of past policy failures:

The list would include in no particular order, the pre-existing failure of educational outcomes, which lead to a largely non-literate indigenous citizenry, extreme housing shortages for personnel required to deliver government funded programmes and service across remote Australia; poor law enforcement and less than optimal levels of intellectual capital within government agencies relevant to remote service delivery ... The combined absence of social and physical infrastructure means that there is nothing for governments to graft mainstream services onto as happens elsewhere. Government appear to discount or underestimate the importance of a pre-existing network of social, physical governance and business infrastructure ... (Dillon and Westbury 2007, p. 59).

One important source of equality in services for Australians is the periodic determinations of the Commonwealth Grants Commission (CGrC). Via complex metrics, the CGrC attempts to equalise funding for service provision around Australia. But there are several problems. First, determinations are based on average or mainstream needs. There are no special provisions or allowances for remedying acute backlogs such as those that exist in remote Australia. These were comprehensively documented by the CGrC in its 2001 report.

Second, while the Commission grants money on the basis of an assessment of needs in particular areas like housing, transport etc., there is no requirement for governments to spend their allocations in these areas. The states and territories are free to spend as they choose. Indeed, the states and territories may also use the existence of special Commonwealth programs as a ground for reducing their own allocations to Indigenous services.

There is no mechanism to check that funds are spent in line with the principles behind their allocation. A significant proportion of the funds allocated by both the CGrC and the Commonwealth to the Northern Territory are in recognition of the special needs of Indigenous Australians. According to a Northern Territory Council of Social Services analysis of the 2008 Northern Territory budget:

The spending priorities of the NT government exacerbate the differences in measures and senses of equality for low-income and disadvantaged people thereby contributing to the reduced life expectancy, poor health, violence and other differences that they are intended to address (NTCOSS 2008; see also The Australian, 24 October 2009). 
Another issue concerns allocations to local government. These are determined on a per capita basis:

The bizarre result is that jurisdictions like the Northern Territory with one sixth of the Australian land mass receive less in local government assistance than is notionally allocated to the population of Geelong (Dillon and Westbury 2007, p. 188).

\section{Whole-of-government policy development: A case study of CDEP}

Whole-of-government is difficult to achieve not just in on-the-ground delivery, but also in processes of cross-departmental policy development. Despite its popularity and considerable impact in remote Australia, at the same time as it is promulgating ambitious employment targets, the government is also curtailing the Community Development Employment Project (CDEP). At its peak, CDEP engaged some 40,000 people:

From 2005, CDEP has been systematically dismantled ... Without much evidence, CDEP is being blamed for cost shifting by governments and for poor mainstream employment outcomes ... as CDEP is dismantled people will be given the choice of mainstream work or welfare, on the proviso that work might require migration from home communities ... This policy change fails to recognise Indigenous aspirations, cultures and life projects (Altman 2009, p. 8).

The specific situation of citizens in remote Australia has seemingly received short shrift. What is to be done in remote communities where there is zero conventional economic infrastructure? For example, to illustrate the effectiveness of CDEP, Altman describes the experience of the Kuninjku community in west Arnhem Land:

For the majority of Aboriginal people in remote communities migration away from ancestral lands ... and from extended kin networks will be neither an aspiration nor a solution. This in turn suggests that key institutions like CDEP that are currently being dismantled will need to be retained (Altman 2009, p. 13).

He notes the specific contributions of CDEP to the Kuninjku economy: harvesting game for local consumption; producing art for sale in the national and global art market; and being employed in paid provision of environmental services.

A review of CDEP by the Department of Finance (2009) found that the scheme had very limited success in fulfilling its work readiness charter and that it was 
almost impossible to assess its community development contribution. It also noted these goals are likely to conflict. Altman's (2011) detailed evidence that the scheme had worked positively as an enabler of remote livelihood possibilities in the hybrid economy played no role in the finance assessment.

The changes to the CDEP scheme in the Northern Territory also indicate the difficulties government faces in managing policy development on a whole-ofgovernment basis. The reductions in CDEP employment displaced populations from outstations and other settlements. But the scheme was run down without town camp capacities being augmented. Moreover, there was no development of new town-based employment opportunities and no or little opportunity for mainstream employment.

\section{Beyond whole-of-government: Squaring the circle between central accountability and place-centred governance}

The previous section catalogued the structural difficulties that have hampered realisation of whole-of-government aspirations. These include the relevance of local contexts; high and increasing transaction costs; a turn to micromanagement; the confounding of freedom of action on the part of local staff; and, above all, the incompatibility between highly centralised organisational, $\mathrm{HR}$ and funding protocols and local discretions. In this respect, Australian experience matches that of other jurisdictions, which have tried whole-ofgovernment and found it wanting. In search of remedies, a number of new or supplementary frameworks have been introduced to shift the locus of choice and decision away from highly centralised arrangements towards more localised contexts. This is reflected both in the 'Total Place' (HM Treasury and Department of Communities and Local Government 2010) initiatives in England and in the attention to place-based approaches in current OECD work. In both cases, the drastic cuts in public spending following the 2008 global financial crisis have coloured implementation (for example, Crowe 2011). Also relevant are 'learning-by-doing' approaches which offer a new accountability framework to reconcile national concerns with local initiative and freedom of action. Finally, imaginative 'place-based' developments, covering the provision of otherwise threatened local services and the realisation of efficiencies through collaboration between authorities at the local level, are also evident in Australia. These are detailed in a comprehensive report on local government in outback Queensland (Dollery and Johnson 2007). These varied governance designs are reviewed in turn. A concluding section explores the consistency of these approaches with recent official reviews of the public sector in Australia. 


\section{The 'Big Society' in Britain}

The coalition government in Britain has sought to implement more decentralised governance arrangements via its 'Big Society' agenda. ${ }^{4}$

Decentralised governance represents a deliberate shift away from the topdown pattern which was common to both the Thatcher-Major and BlairBrown governments. In particular, the Blair-Brown years were marked by substantially increased investment in the public sector and the development of arrangements to enhance central control, but in conjunction with whole-ofgovernment delivery at the local level. Organisational arrangements to buttress central control and to drive service improvement included special units in the Cabinet office to facilitate strategy development and to drive program change. In addition, the performance framework was extended with a plethora of targets and measures. To facilitate joined-up working, joint funding agreements were also introduced. There is an extensive literature on all these developments (for example, Parker et al. 2010; Barber 2008; Marsh and Miller 2012, particularly chapters 3 and 4).

The profound limitations of this experience fanned interest in more radically decentralised approaches. An early move occurred in 2006 when the Lyons review of local government proposed attention to place-based approaches. In subsequent years, within and beyond government, attention to alternatives flourished. Think tanks have been important contributors to the emerging agenda (for example, Demos (Wind-Cowie 2010); Institute of Public Policy Research 2010; Institute for Government (Adonis and Sims 2011); New Economics Foundation (Coote 2010)). In addition, the House of Commons Public Administration Committee and the Communities and Local Government Committee have serially reviewed aspects of the new approach. ${ }^{5}$

The government has since taken several steps to advance its decentralising agenda, notably the establishment of its Whole Place Community Budgets Programme. This sought to shift the initiative in service design from central to place-based authorities. It sought to join up relevant central and local

\footnotetext{
4 Greg Clark (now a minister in the British government) wrote a book in 2003 which he describes as making the case that 'if central government is everywhere, then local government is nowhere' (Clark 2003).

5 A comprehensive list of House of Commons committee enquiries on community budgets and the 'Big Society' follows: Community Budgets (Communities Select Committee 2013); Integration across Government and Whole-Place Community Budgets (Public Accounts Committee 2013); Taking Forward Community Budgets (Communities SC 2012); Localisation Issues in welfare reform (Communities SC 2011); Mutual and Co-operative approaches to delivering local services (Communities SC 2012); Localism (Communities SC 2011); The Big Society (Public Admin Select Committee 2011); Further Report on The Big Society (Public Admin SC 20912); Citizens and public services (Public Admin SC 2013); Department of Communities and Local Government: Financial sustainability of local authorities (PAC 2013).
} 
departments and agencies (and, where appropriate, NGOs and the private sector) to create proactive services that could be responsive to specific local or client circumstances and needs. The promise was greater impact at less cost.

Four English pilots have now been successfully completed. The program was administered by the Department of Communities and Local Government. In essence, this program brought together public and private sector bodies to develop new ways of delivering local services. It aimed to increase efficiency and improve service outcomes through more integrated service provision across multiple agencies. The project commenced in 2011 and local authorities were invited to apply to participate in the pilots.

The pilots involved joint project teams from central government and the relevant authorities. The teams first mapped highest cost services/categories and then sought to devise joined-up programs. This work was supported by five technical advisory sub-groups, each focusing on developing a methodology for a specific policy area: health and adult social care; criminal justice; families with complex needs; the economy; and education and early years. These groups identified sources of information on unit costs and outcomes and promoted consistency in assumptions.

The approach is described in detail in evidence to the Communities Select Committee (Localism HC 547, 7 June 2011), in an NAO report ( 2013) and also in a comprehensive report for the Local Government Association (2013).

The following is a brief sketch of each pilot:

West Cheshire: Total public service spends in the area in 2010-2011: $£ 2.4$ billion. A Public Services Board was established to provide overall strategic and managerial direction. The project united local authorities with four central departments (Health, Justice, Education, and Home Office). Collaboration was developed around five themes: starting well (early intervention in complex families); working well (local economic growth, work ready individuals); living well (community empowerment, safer communities, affordable housing); ageing well (home services); and smarter services (integrated asset management, poled customer insight, data sharing, strategic commissioning). Estimated savings: $£ 56$ million over five years.

Essex: Total public service spend in the area in 2010-2011: £12.8 billion. This involved 15 local authorities. An Executive Board was established. Collaboration was developed around four themes: families with complex needs; economic opportunity (focused on skills and infrastructure); community safety (reducing reoffending and domestic abuse); and health and well-being (focused 
on integrated commissioning). Estimated $£ 414$ million in net benefits over six years, comprising $£ 127$ million of cashable savings and $£ 287$ million of economic, social and fiscal benefits.

Greater Manchester: Total public service spend in the area in 2010-2011: £21 billion. The project involved 10 unitary authorities represented by the Greater Manchester Combined Authority. There were four themes: early years (school readiness, links to 'troubled families' work stream); worklessness; reducing reoffending (young people, women and repeat offenders); and integrated health and social care (dementia and psychiatric, drugs and alcohol, end-of-life, fit-forwork, acute conditions). $£ 270$ million of net savings over five years

West London Tri-borough: Total public service spend in the area in 2010-2011: $£ 6$ billion. Involved three London boroughs: Westminster, Kensington and Chelsea, Hammersmith and Fulham. Oversight through an established board. Themes included troubled and complex families; work and skills; health and social care; strategic coordination of infrastructure. Collaborative planning commenced in 2011 and involved shared library, adult social care, and children's services across three boroughs. This is to be extended to integration of public health functions and corporate services covering ICT and facilities. Estimated $£ 70$ million of net savings annually

The National Audit Office (NAO) assessment (NAO 2013) supported these initiatives. The report also highlighted the need to develop more robust, standardised measurement tools as experience accumulated. As a result of these experiments, more robust methodologies are being developed to measure savings and to allocate contributions, 'including financial incentives or funding arrangements that encourage partners to invest across organisational boundaries, particularly where reform takes longer to be financially viable' (NAO 2013, p. 10).

As might be expected, in a change on this scale the development of methodologies and protocols remains a work-in-progress - refined arrangements remain to be fully developed in a number of areas including:

- standardised information and information sharing protocols;

- a protocol concerning the sharing of savings, particularly where costs and benefits accrue to different agencies and/or over significantly different time periods;

- how incentives for participation can be maintained and strengthened over a program whose pay-offs are relatively long term; and

- how accountability structures might be reframed. 
The NAO also commented: 'The anticipated savings from this initial exercise may appear modest compared with total public expenditure. However it is still early days ... Importantly, the current exercise focused on testing a new way of working rather than maximising the results over the short term' (NAO 2013, p. 24).

The program described above has involved methodologies for co-funding between departments and agencies, and has also shown how initial protocols might be developed surrounding accountability, HR assignments, and the sharing of returns.

But the enduring success of this approach also requires a public service culture that is open to innovation. This involves prioritising, as a subject for routine attention, continuous improvement via service design. Here the Cameron government has commissioned six independent bodies to constitute what it has termed 'What Works Institutes'. Their remit is exercised under the auspices of the Cabinet Office. Their role is to identify sectors of pressing social need and major public spending, where an evidence base exists but where this is either not synthesised authoritatively or where communication of findings is deficient. The aim is to aid strategic and operational development and day-to-day practice amongst at least three distinct groups:

- Commissioning staff: In areas where services are delivered by NGO or forprofit contracts, the institutes will assist those who commission services in informing their decisions on how best to spend public money;

- Service managers: In areas of direct service provision, the institutes will assist public services managers in establishing how best to deliver public services and how to improve their service; and,

- Policy managers: In policy design, the institutes will assist departments in developing an informed view of what is and is not cost effective in public services.

The six centres cover: health and social care, education attainment, ageing better, local growth, crime reduction, and effective early intervention. Together these centres cover some $£ 200$ billion of public spending.

To ensure research outputs are utilised by government, a senior civil servant has been appointed as National Advisor to engage with ministers and other stakeholder groups. This officer is located in the Cabinet Office and reports to the Minister for Government Policy and the Chief Secretary to the Treasury. 


\section{Place-based approaches in recent OECD work}

The extent and variety of place-based approaches in recent OECD studies indicate the emergent appeal of this framework. In the quest for sustainable economic development, jobs and the effective provision of public services, the establishment of context-specific capabilities are seen to be primary. They represent the next move in the development of public management. Placebased approaches are suggested for a variety of contexts including economic development and innovation, social development, city and rural development, unemployment, deprived areas, and high needs contexts. This is indicated in the following list of recent studies (with additional studies listed in the footnote):

- Managing Accountability and Flexibility in Labour Market Policy (2011)

- Breaking out of Policy Silos: Doing more with less (2010)

- Strategies to Improve Rural Service Delivery (2010)

- Regions Matter: Economic Recovery, Innovation and Sustainable Growth (2009)

- How Regions Grow: Trends and Analysis (2009)

- Linking Regions and Central Government: Contracts for Regional Development (2007)

- Governing Regional Development Policy: The Use of Indicators (2009)

- Flexible Policy for More and Better Jobs (2009)

- Linking Regions and Central Government: Contracts for Regional Development (2007)

- The New Rural paradigm: Policies and Governance (2006) ${ }^{6}$

One proposition is common to these reports: while it is paramount to get institutions right at the local or regional level, there is no one-size-fits-all solution. According to one OECD analyst:

In many countries, the regional/central vertical governance gap is significant: the centre faces information gaps and the regions confront capacity gaps. Moreover, it makes little sense to speak of 'centralisation' or decentralisation in general - the details are always the key (Coleman 2010).

Historic, institutional and local characteristics should shape governance designs. For example, in relation to development, the emphasis is on differentiated

6 Delivering Local Development through a Comprehensive Approach to Strategy, System and Leadership: Highlighting the case of Derry-Londonderry, Northern Ireland (2011); New Approaches to Rural Policy: Lesson for around the world (2005); The New Rural Paradigm, Policies and Governance (2006); OECD Territorial Reviews: France (2006); Job Rich Growth: Strategies for local employment, skills development and social protection (2011); OECD Science, Technology and Industry Outlook (2010). 
strategies and organisational designs which can detect and then exploit existing or potential niches or opportunities. Implicit in all of the foregoing is the key role of local engagement and empowerment.

In designing place-based arrangements, the OECD has developed two frameworks. The first sets out systematically the seven core dimensions of a governance system: information, capacity, funding, policy, administration, objectives and accountability (see Table 1). These individual elements are defined as follows (Chairbit 2011):

i. An information gap is characterised by information asymmetries between levels of government when designing, implementing and delivering public policies. Sometimes the information gap results from strategic behaviours of public actors who may prefer not to reveal too clearly their strengths and weaknesses, especially if allocation of responsibility is associated with conditional granting. However, it is often the case that the very information about territorial specificities is not perceived by the central decision maker whilst sub national actors may be ignorant about capital objectives and strategies.

ii. The capacity challenge arises when there is a lack of human knowledge or resources available to carry out tasks, regardless of the level of government (even if, in general sub national governments are considered to be suffering more from such difficulties than central government).

iii. The fiscal gap is represented by the difference between territorial revenues and the required expenditures to meet local responsibilities and implement appropriate development strategies. In a more dynamic perspective, fiscal difficulties also include mismatch between budget practices and policy needs: in the absence of multi-annual budget practices for example, local authorities may face uncertainty in engaging in appropriate spending, and/or face a lack of flexibility in spending despite its appropriateness in uncertain contexts. Too strict earmarking of grants may also impede appropriate fungibility of resources and limit ability to deliver adapted policies.

iv. The policy challenge results when line ministries take a purely vertical be implemented at the territorial level. By contrast, local authorities are best to customise complementarities between policy fields and concretise cross-sectional approaches. Limited coordination among line ministries may provoke a heavy administrative burden, different timing and agenda in managing correlated actions etc. It can even lead to strong inconsistencies when objectives of sectoral policymakers are contradictory. 
v. The administrative gap occurs when the administrative scale for policy making, in terms of spending as well as strategic planning, is not in line with relevant functional areas. A very common case concerns municipal fragmentation which can lead jurisdictions to initiate ineffective public action by not benefitting from economies of scale. Some specific policies also require very specific and often naturally fixed, boundaries.

vi. The active gap refers to different rationalities from national and subnational policymakers which create obstacles for adopting convergent strategies. Common examples arise from political and departmental purposes. Divergences across levels of government can be used for 'cornering' the debate instead of serving common purposes. A local mayor may prefer to serve constituents perceived aspirations instead of aligning decisions to national or state wide objectives which may be perceived as contradictory.

vii. The accountability challenge results from the difficulty to ensure transparency of practices across different constituencies and levels of government. It also concerns possible integrity challenges of policymakers involved in the management of public investment.

These 'gaps' together constitute the architecture that is essential for effective place designs. In the absence of appropriate arrangements in any one building block, the entire design of place governance is put at risk. In turn, this emphasises the significance of a diagnostic phase in which local conditions, needs and circumstances need to be clearly identified.

The second framework, 'Bridging Coordination and Capacity Gaps' (see Table 2 ), illustrates the approaches adopted in various states to overcome coordination and capacity gaps. A particular state might use various combinations of these instruments, depending on what it seeks to achieve through decentralisation and what coordination and capacity gaps are relevant. The key point again is the variety of approaches that are evident around OECD states and the specifically local character of any particular design. 


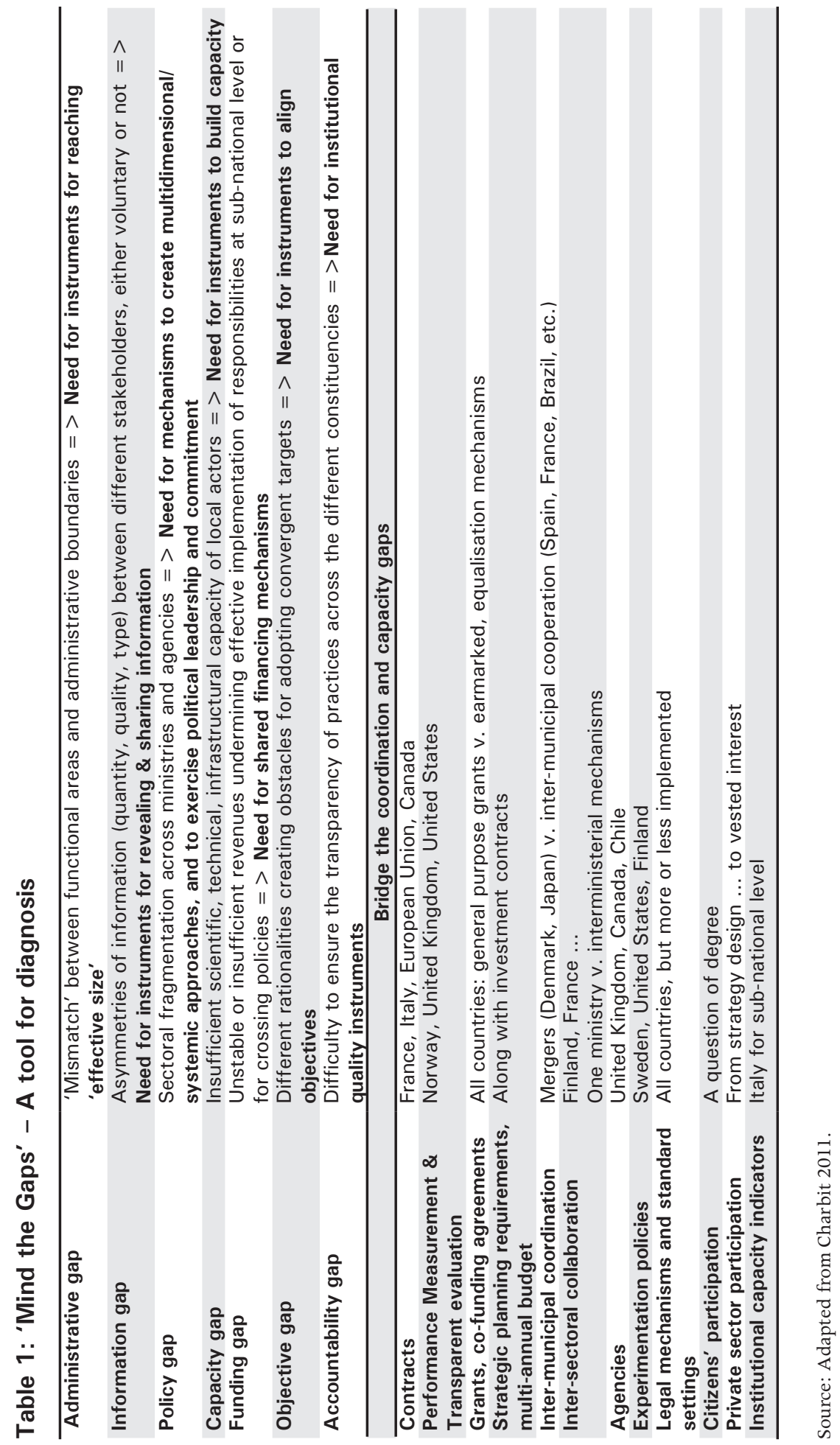


A decentralised approach is reinforced in literatures on regional innovation systems to which we now turn.

\section{EU 'learning-by-doing', experimentalist or pragmatist governance}

The European Union (EU) is a complex multi-level governance design for which it is hard to find precedents. In areas where common action has been agreed, the diversity of approaches and structures between member states ruled out top-down or one-size-fits-all designs. So how could action be coordinated? In answering this latter question, the EU has introduced an approach which may have applications to coordinated action between and within levels of government in Australia, specifically in the context of remote Australia.

The EU approach replaces principal-agent designs with a 'learning-by-doing' or pragmatist one (Sabel and Zeitlin 2011). The former design continues to dominate public policy thinking in Australia. A central tenet of principalagent theory is that the principal can determine desired outcomes in advance. Pre-determined performance metrics allow the principal to hold the agent accountable for outcomes, thus obviating shirking, opportunism and other deceptive behaviour on the part of the agent. This has been widely applied in public sector settings in Australia - in a variety of human services contracts, for example (see Marsh and Spies-Butcher 2009). But the diversity of conditions across the country has required adaptation. Hence in equalising comparisons the centre adds in a variety of qualifying factors that it considers appropriate. Influenced by this thinking, elaborate contractual, co-production, outsourcing and reporting structures have developed in a variety of fields (for example, surveyed in Productivity Commission 2010).

At least three basic features of human service (and other) contexts undercut advance determination of outcomes by a centrally located principal:

- First, the knowledge guiding the decisions of both principals and agents is provisional: both are operating with corrigible information and judgements. Unintended consequences, ambiguity and difference abound. It is impossible to devise programs from first principles that survive the effort to realise them. In the case of the principal, this involves judgements about attainable outcomes and, in the case of agents, this involves judgements about the practices most likely to enhance performance in the pursuit of these outcomes.

- Second, providers have information that is essential to adapting performance outcomes for the overall system that recognise best practice: the principal is setting outcomes that need to reconcile efficiency and quality in a way that 
minimises incentives for provider gamesmanship, creates incentives for efficiency and that does so in a way that also promotes quality services for clients. Any one of the outcomes is complex. Their achievement in combination is a daunting challenge. Only the providers have information that is relevant to making this latter judgement. The principal needs routine access to provider information in order to refine and develop her understanding of desired outcomes in the light of provider and client experience.

- Third, providers' own knowledge of how to attain quality services for clients is varied and developing: providers' own knowledge of how best to serve clients - and how best to establish organisational and governance routines that reinforce these outcomes - is itself corrigible and experimental. Different organisations will attain different outcomes and it will not be immediately apparent which represents the best achievement of not necessarily consistent purposes. Dynamic efficiency through the whole system thus requires the routine collection, assessment and dissemination of performance information amongst providers.

An 'experimentalist' or pragmatist approach represents an alternative to these architectures, but one that promises to shift exchanges from a primarily punitive to a primarily learning basis (Sabel 2004; Sabel and Zeitlin 2011). This builds on earlier work on continuous performance improvement and 'learning by doing' - an approach to dynamic efficiency that was developed by the Toyota Motor Company in its management of buyer-supplier relationships (Sabel 1992). Here is how this might be translated to public policy settings:

General goals or designs are set provisionally by the highest level parliament, a regulatory authority, or the relevant corporate executives ... then the provisional goals are revised in the light of proposals by lower level units responsible for executing key aspects of the overall task (Sabel 2004, p. 11).

Sabel proposes to recast fundamentally the terms of the accountability relationship between principals and agents:

Compliance or accountability in the principal agent sense of rule following is There are in effect no fixed rules, or, what comes to the same thing, a key rule is to continuously evaluate possible changes in the rules. Accountability thus requires not comparison of performance to a goal or rule, but reason giving: actors in the new institutions are called upon to explain their use of the autonomy they are accorded in pursuing the corrigible goals [emphasis mine]. These accounts enable evaluation of their choices in the light of explanations provided by actors in similar circumstances making different ones and vice versa. 
Agents who fail to perform to best-practice levels are first given the chance to improve via an exchange of knowledge about their potential to improve: 'Repeated failure to respond, even with assistance, is, however, likely to bring about the dissolution of the offending unit' (Sabel 2004, p. 14). This broad approach has been widely tested in a variety of human services and other public policy settings in the US (Sabel and Simon 2010).

Pragmatist or experimental principles define an approach to the management of intergovernmental and purchaser-provider relations wholly different from the structure that is now dominant in federal and state jurisdictions. The alternative 'experimentalist' or pragmatist approach to system design builds on a broad structure of intergovernmental and purchaser-provider relationship, but places exchange in a context that emphasises learning by both parties.

\section{Australian local government practice}

The foregoing discussion focused on regions as the relevant spatial unit and involved governance models drawn from international practice. Parallel experiments and possibilities are also evident in Australian local government practice. The models that have been developed here have clear implications for imagining various possible forms of regional governance. These local government arrangements are comprehensively explored in a report of the collaborative practices of shires in remote Queensland (Dollery and Johnson 2007). The report documents the many imaginative responses of individual councils to preserve community amenities and to reconcile local responsiveness with efficient resource management and relationships with other levels of government. The focus of the report is the Remote Area Planning and Development Board which is a not-for-profit, Australian Securities and Investments Commission-listed company involving a collaboration of 11 councils in western Queensland. Its core concerns are transport, regional planning, capacity building, natural resource management, service development, technology and communications, development of sustainable industries, and investment attraction.

The report documents the many imaginative roles that are being undertaken by the individual councils to ensure community amenities are maintained at desired standards:

In the absence of any other feasible service providers, local councils must provide a large range of essentials services. For instance, there are not many councils in Australia that provide the postal services (as in Barcoo and Ilfracombe); offer banking facilities (Blackall, Boulia, Tambo and Winton); a café (as in Boulia, Isisford and Winton); undertaker services (Barcoo, Blackall, Boulia, Ilfracombe and Tambo); real estate agency 
activities (Diamentina); operate general stores (Ilfracombe and Isisford); provide freight services (Isisford); or operate the local newspaper (Blackall) ... In addition, each council provides extensive support to the humorous community and sporting organisations in their boundaries (Dollery and Johnson 2007, p. 104).

Other services include:

Aramac Shire either directly or indirectly provides ... a bakery, Home and Community Care programs, and a rural transaction centre. Similarly, Barcaldine Shire delivers a number of state government programs including rural family support, 60 and Better, Home Assist Secure and a HACC program ... BARCO Shire Council provides the Jundah Post Office ... the Council provides a bus service and a 4WD vehicle for the three schools in the Shire; the Council provided land for the Windorah Medical Clinic; it provided land for state community housing; it has undertaker services and provides burial services ... Barcoo Shire has set up a bursary system for residents undertaking tertiary, diploma or trade qualifications ... Blackall Shire assist its residents by providing an 'in-store' Westpac Bank facility in the Council office and it acts as a 'developer' baby providing an industrial estate as well as residential land for sale ... [it] runs an extensive local economic development program ... an airport (with 3 commercial flights a week); SBS radio transmission; youth development services, including employment initiatives (Dollery and Johnson 2007, p. 105-106).

\section{Conclusion}

The foregoing suggests the timeliness of a shift of governance towards more place-based spatial levels. This is the next logical step in the development of public sector governance. As noted at the outset, this is wholly consistent with the vision for public sector reform advanced in a number of recent official reports; for example, at the federal level, in the Moran Review (AGRGA 2010); and at a state level, in the Western Australian Economic Audit Committee Report (WAEAC 2009). This latter report specifically foreshadows the replacement of 'agencies operating in silos' with more decentralised citizenfocused arrangements. Both these reports underline the profound challenge to centralised processes, cultures and organisational and budgetary protocols that are involved in a further iteration of public sector reform. The evidence reviewed in the last section suggests governance designs are available - but, as British experience attests, the difficulties in translating aspirations into practice remain formidable. No less profound obstacles can be anticipated in Australia. 
Indeed here they are compounded by intergovernmental considerations. On the other hand, both fiscal and political imperatives imply dictate a shift to citizen focused services. The demand for more proactive services that are and sensitive to context will not go away. In charting a new path, a first challenge is to imagination - there is another way.

\section{References}

Adonis, A. and S. Sims 2011, Mayors and the Localism Bill, Institute for Government, Carlton Gardens.

AGRGA (Advisory Group on Reform of Australian Government Administration) 2010, 'Ahead of the Game: Blueprint for the teform of Australian government administration'. Available at: http://www.dpmc.gov.au/publications/aga_ reform/aga_reform_blueprint/docs/APS_reform_blueprint.pdf.

Altman, J. C. 2009, 'Beyond Closing the Gap: Valuing diversity in Indigenous Australia', CAEPR Working Paper No. 54. Available at: http://caepr.anu.edu. au/Publications/WP/2009WP54.php.

Altman, J. C. 2011, ‘The Draft Indigenous Economic Strategy: A critical response', CAEPR Topical Issue No. 3. Available at: http://caepr.anu.edu.au/ Publications/topical/2011TI3.php.

ANAO (Australian National Audit Office) 2007, 'Whole-of-Government Indigenous Service Delivery Arrangements', ANAO Audit Report No 10. Available at: http://www.anao.gov.au/Publications/AuditReports/2007-2008/Whole-of-Government-Indigenous-Service-DeliveryArrangements.

Australian Government 2011, 'Engaging Today, Building Tomorrow: A framework for engaging with Aboriginal and Torres Strait Islander Australians.

Barber, M. 2008, Instruction to Deliver: Fighting to transform Britain's public service, 2nd ed., Methuen, London.

Communities and Local Government Select Committee 2011a, 'Localism', Third Report, 9 May. Available at: http://www.publications.parliament.uk/pa/ cm201012/cmselect/cmcomloc/547/547.pdf.

Charbit, C. 2011, 'Governance of Public Policies in a Decentralised Contexts: The multi-level approach', OECD Regional Policy Development Working Paper 2011/04. Available at: http://www.oecd.org/governance/regionalpolicy/48724565.pdf. 
New Accountabilities, New Challenges

Clark, G. 2003, Total Politics: Labour's Command State, Conservative Policy Unit, London.

Coleman, W. 2010, Presentation to Australian MPs, October, 2010.

Commonwealth Grants Commission 2001, 'Indigenous Funding Inquiry: Final report'. Available at: https://cgc.gov.au/index.php?option=com content\&view =article \&id = 53:2001-indigenous-fundinginquiry \& catid $=39 \&$ Itemid $=160$.

Coote, A. 2010, 'Cutting It: “The Big Society" and the new austerity', New Economics Foundation, London.

Crowe, J. 2011, 'The Government's Plans for Decentralisation and Localism: A progress report', The Political Quarterly 82(4), pp. 651-657.

Department of Finance 2009, 'Review of the CDEP Scheme'. Available at: http://www.anao.gov.au/ /media/Uploads/Documents/evaluation_of_the_ community_development_employment_projects_(cdep)_program.pdf.

Department of Finance 2010, 'Strategic Review of Indigenous Expenditure'. Available at: http://www.finance.gov.au/sites/default/files/foi_10-27_ strategic_review_indigenous_expenditure.pdf.

Dillon, M. and N. Westbury 2007, Beyond Humbug: Transforming government engagement with Indigenous Australia, Seaview Press, South Australia.

Dollery, B. and A. Johnson 2007, 'RAPAD (Remote Area Planning and Development Board) Report: Sustaining outback communities', University of New England, Armidale.

Dorf, L. and C. Sabel 1998, 'A Constitution of Democratic Experimentalism', Columbia Law Review 98, pp. 267-473.

Edmunds, M. 2010, The Northern Territory Intervention and Human Rights: An anthropoligical perspective, Whitlam Institute, University of Western Sydney, Bankstown.

FaHCSIA (Department of Families, Housing, Community Services and Indigenous Affairs) 2004, 'Evaluation of ICCs'. Available at: https://www.dss.gov.au/ sites/default/files/documents/06_2012/icc_review_report_0.pdf.

Gray, B. 2006, 'COAG Trial Evaluation, Wadeye, Northern Territory', WJG and Associates. Available at: http:/www.territorystories.nt.gov.au/ handle/10070/143460. 
Gray, W. and W. G. Sanders 2006, 'Views from the Top of the "Quiet Revolution": Secretarial perspectives on the new arrangements in Indigenous affairs', CAEPR Discussion Paper 282/2006. Available at: http://caepr.anu.edu.au/ Publications/DP/2006DP282.php.

H. M. Treasury and the Department of Communities and Local Government 2010, 'Total Place: A Whole Area Approach to Public Services'. Available at: http://webarchive.nationalarchives.gov.uk/20130129110402/http:/www. hm-treasury.gov.uk/d/total_place_report.pdf.

Hunt, J. 2007, ‘The Whole-of-Government Experiment in Indigenous Affairs: A question of governance capacity', Public Policy 2(2), pp. 155-174.

Institute of Public Policy Research 2010, 'Capable Communities: Towards citizenpowered public services', Institute of Public Policy Research, London.

KPMG 2007, 'Evaluation of Indigenous Coordination Centres. Available at: www. dss.gov.au/sites/default/files/documents/06_2012/icc_review_report_0.pdf.

Local Government Association 2013, 'A Guide to Whole Place Communicty Budgets'. Available at: http://www.local.gov.uk/community-budgets/-/ journal_content/56/10180/3930626/ARTICLE.

Management Advisory Committee 2004, 'Connecting Government: Whole of government responses to Australia's priority challenges', Australian Public Service Commission, Canberra.

Management Advisory Committee 2007, 'Note for file: A report on recordkeeping in the Australian Public Service', Australian Public Service Commission, Canberra.

Marsh, I. and R. Miller 2012, Democratic Decline and Democratic Renewal: Political change in Britain, Australia and New Zealand, Cambridge University Press, Cambridge.

Marsh, I. and B. Spies-Butcher, 2009, 'Pragmatist and Neo-classical Policy Paradigms: Which is the best template for program design?', Australian Journal of Public Administration 68(3), pp. 239-255.

Morgan Disney and Associates 2006, Synopsis Review of the COAG Trial Evaluation. Available at: https://www.dss.gov.au/sites/default/files/ documents/05_2012/coag_trials_overview.pdf.

NAO (National Audit Office) 'Case Study on Integration: Measuring the costs and benefits of whole-place community budgets'. Available at: http://www.nao. 
org.uk/press-releases/department-for-communities-and-local-governmentcase-study-on-integration-measuring-the-costs-and-benefits-of-wholeplace-community-budgets-2/.

NTCOSS (Northern Territory Council of Social Services) 2008, 'Submission to the Enquiry into Government Expenditure on Indigenous Affairs and Social Services in the Northern Territory'.

NTER Review (Northern Territory Emergency Response Review) 2008, Department of Families, Housing, Community Services and Indigenous Affairs, Canberra.

O'Flynn, J., F. Buick, D. Blackman and J. Halligan 2011, 'You Win Some, You Lose Some: Experiments with joined-up government', International Journal of Public Administration 34(4), pp. 244-254.

Parker, S., A. Paun, J. McClory and K. Blatchford 2010, Shaping Up: A Whitehall for the future, Institute for Government, London.

Productivity Commission 2010, 'Contribution of the Not-for-Profit Sector'. Available at: http://www.pc.gov.au/_data/assets/pdf_file/0003/94548/notfor-profit-report.pdf.

Productivity Commission 2012, 'Indigenous Expenditure Report' Steering Committee for the Review of Government Service Provision. Available at: http://www.pc.gov.au/gsp/ier.

Rowse, T. 2002, Indigenous Futures, Choice and Development for Aboriginal and Islander Australia, UNSW Press, Kensington.

Rowse, T. 2012, Rethinking Social Justice: From 'peoples' to 'populations', Aboriginal Studies Press, Canberra.

Sabel, C. 1992, 'Learning by Monitoring: The institutions of economic development', in L. Rodwin and D. Schon (eds) Rethinking the Development Experience: Essays provoked by the work of Albert O. Hirschman, The Brookings Institution, Washington.

Sabel, C. 2004, 'Beyond Principal-Agent Governance: Experimentalist organisation, learning and accountability', in E. R. Engelen and M. S. D. Ho (eds), De Staat van de Democratie: Democratie voorbij de staat, Amsterdam University Press, Amsterdam.

Sabel, C. and W. Simon 2010, 'Minimalism and Experimentalism in the Administrative State', The Georgetown Law Review 100, pp. 54-93. 
Sabel, C. and J. Zeitlin 2011, 'Experimentalist Governance', in D. Levi-Faurr (ed.), The Oxford Handbook of Governance, Oxford University Press, Oxford.

Shergold, P. 2006, 'Indigenous Economic Opportunity: The role of the community and the individual', speech delivered to First Nations Economic Opportunity Conference, 19 July. Available at: http://www.google.com.au/url?q=http:// www.ceo.wa.edu.au/listserver/cwac/doc00001.doc\&sa=U\&ei=C8QfVJDoJ Mbe8AX4xYIw\&ved=0CBoQFjAB\&sig2=RqytPYuXH648eJW 16CA5dg\&us $\mathrm{g}=$ AFQjCNEyzWndLLGxvE9ay761M6iVlxS10A.

Shergold, P. 2013, 'An Agenda for Reform of the Australian Public Service', in D. Markwell, R. Thompson and J. Leeser (eds), State of the Nation: Aspects of Australian public policy, Menzies Research Centre, Canberra.

Smith, D. 2009, 'From COAG to Coercion: A story of governance failure, success and opportunity in Australian Indigenous affairs', Paper presented to ANZSOG conference: Governing Through Collaboration: Managing Better Through Others, 28-29 June. Available at: http://caepr.anu.edu.au/others/ governance/Occasional-papers-1190988000.php.

Urbis, Keys and Young 2006, 'Evaluation of the Murdi Paarki COAG Trials'. Available at: www.dss.gov.au/sites/default/files/documents/05_2012/coag_ nsw.pdfWAEAC.

WAEAC (Western Australia Economic Audit Committee) 2009, 'Putting the Public First: Partnering with the community and business to deliver outcomes: Summary report'.

Wind-Cowie, M. 2010, Civic Street: The big society in action, Demos, London. 
This text taken from New Accountabilities, New Challenges, edited by John Wanna, Evert A. Lindquist and Penelope Marshall, published 2015 by ANU Press, The Australian National University, Canberra, Australia. 